\title{
Prudent use of a left hepatic graft in adult-to-adult living donor liver transplantation: aiming for further securing donors' safety
}

\author{
Hideaki Uchiyama \\ Department of Surgery and Science, Graduate School of Medical Sciences, Kyushu University, Fukuoka, Japan \\ Correspondence to: Hideaki Uchiyama. Department of Surgery and Science, Graduate School of Medical Sciences, Kyushu University, Fukuoka, Japan. \\ Email: huchi@surg2.med.kyushu-u.ac.jp. \\ Provenance and Peer Review: This article was commissioned by the editorial office, Hepatobiliary Surgery and Nutrition. The article did not undergo \\ external peer review. \\ Comment on: Huang V, Chen CL, Lin YH, et al. Bilateral proficiency over time leads to reduced donor morbidity in living donor hepatectomy. \\ Hepatobiliary Surg Nutr 2019;8:459-69.
}

Submitted Oct 22, 2019. Accepted for publication Oct 31, 2019.

doi: 10.21037/hbsn.2019.11.04

View this article at: http://dx.doi.org/10.21037/hbsn.2019.11.04

\section{Introduction}

The safety of donors in living donor liver transplantation (LDLT) is of paramount importance. Although the morbidity of LDLT donors has been dramatically decreased, there is still room for further improving the outcomes of LDLT donors (1).

Recently, an intriguing report by Huang et al. entitled "Bilateral proficiency over time leads to reduced donor morbidity in living donor hepatectomy" (2) was published. In this report, they retrospectively reviewed the complication rates of a total of 834 donors, dividing the donors into right hepatic (RH) and left hepatic (LH) graft donors. In addition, they investigated whether bilateral proficiency in donor hepatectomy (i.e., familiarity with procurement and use of not only RH but also LH grafts) improved the overall outcomes in LDLT. They concluded "Accumulating experience with bilateral donor hepatectomy leads to decreased donor morbidity and comparable outcomes for right and left lobes, further enhancing the goal of donor safety while balancing recipient needs". I completely agree with their conclusions. Although RH grafts predominate in adultto-adult LDLT in most centers world-wide, I strongly insist that LH grafts should also be used in selected donorrecipient combinations in order to further improve overall outcomes of LDLT. Here, I would like to summarize my opinions on their results by citing some relevant references.

\section{What are the pros and cons of using left hepatic grafts?}

The pros of using left hepatic grafts

The use of LH grafts leaves a larger amount of hepatic parenchyma in donors (approximately $60 \%$ of the total liver mass), compared to RH donors. As expected, the levels of prothrombin time and total bilirubin in the early postoperative days after living liver donation are significantly lower in LH donors than RH donors $(1,3,4)$, which suggests that the burden of LH graft donation is much lighter than RH. In fact, post-hepatectomy liver failure, intractable ascites, and pleural effusion almost exclusively occur after RH donation $(1,3)$, and most of the devastating consequences after living liver donation occurred in $\mathrm{RH}$ donors $(5,6)$. In this regard, $\mathrm{LH}$ graft donation is absolutely safer than RH graft donation.

Most of the serious complications after living liver donation are biliary-related. Biliary complications had been said to more frequently occur in $\mathrm{RH}$ donors $(7,8)$, but this trend seems to have disappeared in the recent studies $(1,3,6)$. The biliary anatomy of $\mathrm{LH}$ grafts is simpler than that of RH grafts and most LH grafts have a single hepatic duct to be reconstructed, which makes the incidence of biliary complications on the recipient side decrease as well.

Usually, LH grafts are accompanied by the middle 
hepatic vein. Therefore, LH grafts have a maximized venous drainage and most of them have a simple venous orifice. In contrast, RH grafts (mainly leave the middle hepatic vein in donors) may have multiple venous orifices, i.e., the superior right hepatic vein, the inferior right hepatic vein, tributary veins of the anterior sector into the middle hepatic veins, which makes vein reconstructions quite complicated (9).

\section{The cons of using left hepatic grafts}

The greatest fear of using left hepatic grafts is the fact that their absolute mass may be too small to sustain recipients' anabolic and catabolic needs, which results in small-for-size syndrome characterized by hyperbilirubinemia, intractable ascites, and coagulopathy (10). Then, what is the lowest limit? A desirable graft volume is more than $35 \%$ of the recipient's standard liver volume. If an estimated LH graft volume does not meet this criterion, its use is not recommended.

LH grafts may have multiple arteries to be reconstructed compared to RH grafts (11). In general, the diameter and the length of hepatic arteries on LH grafts are thinner and shorter than those on RH grafts. Furthermore, arteries on an LH graft with multiple arteries are much thinner and shorter than arteries on an LH graft with a single artery, which makes hepatic artery reconstruction extremely difficult. Mastering microvascular reconstruction techniques of tiny arteries (preferably under a microscope) is needed for increasing the number of LDLT with LH grafts.

A usual LH graft procurement takes the middle hepatic vein from the donor. This may result in venous congestion of the anterior sector of the remnant donor liver. Therefore, some donor surgeons insist that the burden of LH graft donation is not always lighter than that of $\mathrm{RH}$ graft donation. The function of the congested region secondary to outflow obstruction in the remnant donor liver is approximately $70 \%$ of that in the non-congested region (12). If there are large tributaries of the anterior sector draining into the middle hepatic vein and an estimated well-perfused (intact venous drainage) remnant liver volume is less than $30 \%$ of the total liver volume, the LH graft procurement requires careful consideration.

There are paradoxical increases of complication rates in LH donors irrespective of accumulated experiences $(1,2)$. Accumulated experiences in donor surgery have led to decreased incidences of postoperative complications in $\mathrm{RH}$ donors, but this phenomenon has not appeared in $\mathrm{LH}$ donors. The incidence of postoperative complications in LH donors stayed the same, or rather increased. As Huang stated (2), LH graft procurement has longer operative time and larger blood loss, which suggests that LH graft procurement is more complicated than $\mathrm{RH}$, or mastering $\mathrm{LH}$ graft procurement is time-consuming. Therefore, $\mathrm{LH}$ donors are not necessarily safer than RH donors from the perspective of overall complication rates.

\section{Are there any differences of recipient outcomes between RH and LH grafts?}

Irrespective of concern about small-for-size syndrome in using LH grafts, there weren't any differences reported in the literatures $(6,10,13)$. Of course, recipients who received LH grafts are highly selected (low body weight and low Model of End-stage Liver Disease score). If small LH grafts are exclusively used for recipients irrespective of recipients' body weight or Model of End-stage Liver Disease score, the recipient outcomes must be dismal. The minimal graft weight should be $35 \%$ of the recipient's standard liver volume. For sick recipients (for example, Model of Endstage Liver Disease score $>25$ ), the lower limit should be raised up to $40 \%$ (11).

\section{Bilateral proficiency of donor hepatectomy may improve overall outcomes not only on the donor side but also on the recipient side}

As above-mentioned, the mortality rate of $\mathrm{LH}$ graft donation is lower than that of RH. Most of the previously reported mortality events seemed, more or less, related to the lack of absolute remnant liver volume after liver donation (5). It is desirable that all adult-to-adult LDLTs are performed using LH grafts, but while using LH graft in all cases may make the possibility of donor mortality nearly zero, recipient outcomes would be dismal. If an estimated liver volume of an LH graft is sufficient to the recipient need, the LH graft should be used aggressively in order to achieve mortality zero of living liver donors. In addition, LH graft implantation is simpler and expects less operative time and blood loss than RH graft, which leads to improving overall outcomes on the recipient side as well. "Bilateral proficiency" of donor hepatectomy is needed indeed. 


\section{Future perspectives}

Recently, some transplant centers use a midline incision for procurement of living donor livers without compromising surgical results (14). A less wound pain would lead to early ambulation, which may eventually decrease the incidence of thromboembolic events, and probably urinary tract or pulmonary infection. In addition, a midline incision would lessen the risk of ventral hernia compared to a reverse $\mathrm{L}$ or a Mercedes incision (this complication is classified as a major complication if the repair is done under general anesthesia). In some centers, living donor hepatectomy is done by a laparoscopic or a robotic procedure with the advancement of ergonomics (15), although the safety of these less invasive procedures needs to be validated. Since one of the most common problems in long-term assessment after living liver donation is incisional discomfort (4), these minimallyinvasive procedures would further improve quality of life after liver donation.

Significant association has been observed between center volume and the number of donor complications $(3,14)$. High volume centers have exhibited significantly lower complication rates. In order to maximize the safety of living liver donors, aggregating LDLT performance would be desirable.

\section{Conclusions}

LH graft donation is absolutely safer than $\mathrm{RH}$ graft donation from the perspective of avoiding devastating consequences. However, the overall complication rates after LH graft donation do not much differ from those after RH graft donation probably the lack of proficiency of $\mathrm{LH}$ graft procurement. Needless to say, a rigorous preoperative screening, multidisciplinary perioperative cares, and meticulous operative procedures are needed in order to further decrease overall complication rates in living liver donors. LH grafts should be prudently used even in adultto-adult LDLT when appropriate, in order to improve overall outcomes of LDLT not only on the donor side but also on the recipient side. Physicians dealing with LDLT need to always strive for achieving mortality zero of living liver donors.

\section{Acknowledgments}

Funding: None.

\section{Footnote}

Conflicts of Interest: The author has completed the ICMJE uniform disclosure form (available at https://hbsn. amegroups.com/article/view/10.21037/hbsn.2019.11.04/coif). The author has no conflicts of interest to declare.

Ethical Statement: The author are accountable for all aspects of the work in ensuring that questions related to the accuracy or integrity of any part of the work are appropriately investigated and resolved.

Open Access Statement: This is an Open Access article distributed in accordance with the Creative Commons Attribution-NonCommercial-NoDerivs 4.0 International License (CC BY-NC-ND 4.0), which permits the noncommercial replication and distribution of the article with the strict proviso that no changes or edits are made and the original work is properly cited (including links to both the formal publication through the relevant DOI and the license). See: https://creativecommons.org/licenses/by-ncnd/4.0\%.

\section{References}

1. Uchiyama H, Shirabe K, Nakagawara H, et al. Revisiting the safety of living liver donors by reassessing 441 donor hepatectomies: Is a larger hepatectomy complicationprone? Am J Transplant 2014;14:367-74.

2. Huang V, Chen CL, Lin YH, et al. Bilateral proficiency over time leads to reduced donor morbidity in living donor hepatectomy. HepatoBiliary Surg Nutr 2019;8:459-69.

3. Rössler F, Sapisochin G, Song G, et al. Defining benchmarks for major liver surgery: A multicenter analysis of 5202 living liver donors. Ann Surg 2016;264:492-500.

4. Berglund D, Kirchner V, Pruett T, et al. Complications after living donor hepatectomy: Analysis of 176 cases at a single center. J Am Coll Surg 2018:227;24-36.

5. Trotter JF, Adam R, Lo CM, et al. Documented deaths of hepatic lobe donors for living donor liver transplantation. Liver Transpl 2006;12:1485-8.

6. Goja S, Yadav SK, Saigal S, et al. Right lobe donor hepatectomy: is it safe? A retrospective study. Transpl Int 2018;31:600-9.

7. Taketomi A, Kayashima H, Soejima Y, et al. Donor risk in adult-to-adult living donor transplantation: Impact of left lobe graft. Transplantation 2009;87:445-50.

8. Hashikura Y, Ichida T, Umeshita K, et al. Donor 
complications associated with living donor liver transplantation in Japan. Transplantation 2009;88:110-4.

9. Uchiyama H, Yoshizumi T, Ikegami T, et al. Use of internal jugular vein grafts in reconstructing multiple venous orifices of right hepatic grafts without the middle hepatic vein trunk. Liver Transpl 2017;23:110-6.

10. Soejima Y, Shirabe K, Taketomi A, et al. Left lobe living donor liver transplantation in adults. Am J Transplant 2012;12:1877-85.

11. Uchiyama H, Shirabe K, Kimura K, et al. Outcomes of adult-to-adult living donor liver transplantation in 321 recipients. Liver Transpl 2016;22:305-15.

12. Ninomiya $M$, Shirabe K, Kayashima H, et al. Functional assessment of the liver with gadolinium-ethoxybenzyl-

Cite this article as: Uchiyama H. Prudent use of a left hepatic graft in adult-to-adult living donor liver transplantation: aiming for further securing donors' safety. HepatoBiliary Surg Nutr 2020;9(3):360-363. doi: 10.21037/hbsn.2019.11.04 diethylenetriamine penta-acetate-enhanced MRI in livingdonor liver transplantation. Br J Surg 2015;102:944-51

13. Halazun KJ, Przybyszewski EM, Griesemer AD, et al. Learning to the left: Increasing the donor pool by using the left lobe, Outcomes of the largest single-center north American experience of left lobe adult-to-adult living donor liver transplantation. Ann Surg 2016;264:448-56.

14. Shirabe K, Eguchi S, Okajima H, et al. Current status of surgical incisions used in donors during living related liver transplantation - a nationwide survey in Japan. Transplantation 2018;102:1293-9.

15. Hong SK, Suh KS, Yoon KC, et al. The learning curve in pure laparoscopic donor right hepatectomy: a cumulative sum analysis. Surg Endosc 2019;33:3741-8. 